\title{
Check This Word Out! Exploring the Factors That Affect Students' Vocabulary Learning Using Smartphones via Partial Least Squares
}

\author{
Mohammad Madallh Alhabahba, ${ }^{1}$ Omer Hassan Ali Mahfoodh, ${ }^{1}$ Ambigapathy Pandian, \\ Yazan Mdala Mohammad, ${ }^{2}$ Enas Waleed Ahmed, ${ }^{2}$ Ali Albdour, ${ }^{3}$ and Hussein Al Bazar ${ }^{4}$ \\ ${ }^{1}$ School of Languages, Literacies and Translation, Universiti Sains Malaysia, 11800 Minden, Pulau Pinang, Malaysia \\ ${ }^{2}$ Department of Business Management, Al-Balqa Applied University, Maian Campus, P.O. Box 110, Ma'an 71910, Jordan \\ ${ }^{3}$ College of Business and Administration, Princess Nora Bint Abdul Rahman University, Station A6, King Khalid International Road, \\ P.O. Box 84428, Riyadh 11671, Saudi Arabia \\ ${ }^{4}$ Open University, Saudi Arabia
}

Correspondence should be addressed to Mohammad Madallh Alhabahba; mohd80ma@hotmail.com

Received 2 April 2014; Accepted 19 August 2014; Published 3 September 2014

Academic Editor: Gérard Lassibille

Copyright (C) 2014 Mohammad Madallh Alhabahba et al. This is an open access article distributed under the Creative Commons Attribution License, which permits unrestricted use, distribution, and reproduction in any medium, provided the original work is properly cited.

A rigorous understanding of the use of Smartphones for foreign language vocabulary acquisition is crucial. Employing the technology acceptance model, this study aims to investigate students' behavioural factors affecting Saudi students' attitudes towards employing Smartphones for foreign vocabulary acquisition. Two hundred and seventy-three students studying in a preparatory year programme were surveyed. SmartPLS was employed to analyse the data obtained from the study's sample. The results revealed that perceived usefulness and attitude proved to be significantly and positively related to vocabulary development. In addition, perceived usefulness and perceived ease of use proved to be significant predictors of students' attitudes towards the use of Smartphone for vocabulary learning. However, the study showed that the relationship between perceived ease of use and vocabulary development is not significant. Thus, publishers of dictionaries may find it necessary to take into account the important role played by the design of dictionaries interfaces in facilitating the use of dictionaries in Smartphones. Furthermore, teachers and educators are encouraged to employ creative activities (e.g., word guessing games) that invest students' use of Smartphones to learn vocabularies. Using Smartphones in learning improves interaction among students and teachers. Discussion and conclusions are also provided.

\section{Introduction}

In this technological advanced era, our daily life activities have been influenced by the rapid development of technology around us. This development may give, in this case a repository for learning and knowledge sharing, effective foreign language learning, and it may also help individuals in different fields such as education, marketing, and social interaction. The role of information and communication technology (ICT) in education has some resonance in the current field of vocabulary learning [1]. Technology in education, in the perspective of Arab educators, is either a great tool for motivating students or a disconnection from real classroom learning. Therefore, technology is akin to transform the learning paradigms and, like other attempts influencing students learning process, should evolve around simple and true presentation to the students. Many attempts have been carried out to implement effective technology to facilitate vocabulary learning [2]. For example, mobile-assisted language learning (MALL), which refers to the use of mobiles in a learning situation such as learning new vocabularies [3], has been considered as a growing subarea in this field. Research on mobile learning has revealed that students' role shifted from a passive receiver to more active participant in a learning situation (e.g., vocabulary learning) [4].

Historically, the development of computers has made human lives easier [5]. The integration of computers in 
human lives have also affected human behaviour in many disciplines, such as education, and specifically human behaviour in the educational context [6]. This behaviour has been a major issue among researchers for a long time [6]. In this regard, researchers have carried out several investigations to understand several factors that affect learners' behaviour, which in our case is students, when employing Smartphones in an educational setting [7-10]. However, previous studies have not given careful attention to the use of Smartphones in education process and even fewer investigations have examined students adoption of Smartphones in learning foreign language vocabulary in second or foreign language contexts, specifically in the Arabian context.

The technological era has penetrated the educational practices [11]. That said, on the use of technology in learning situations, ICT tools have put educational practices into a unique framework. In essence, this framework shifts the paradigm of learners and educators from the traditional style of teaching and learning into a different educational style $[12,13]$. The broader areas of investigations of technology adoption could help education policies to change from the chalkboard era to multimedia and more visual learning and teaching $[14,15]$. This may help in understanding what affects individuals' behaviour inside and outside classrooms, particularly when ICT is integrated in learning second or foreign language $[16,17]$. The threads that link most investigations on ICT role in education are the ideas of the value of the technology integration which holds both for students' academic success and for the need to adapt with the introduced technology while the latter is seen as challenging, especially when individuals have a choice of interacting with specific features of the ICT tools for learning or teaching $[18,19]$.

Interesting to note that ICT has driven current changes in the Arab world [20]. In part, this change has been brought to the forefront discussion of current practices of ICT employment in education [21]. This discussion has recently been emphasized by Arab educational bodies. However, the present ICT utilisation in the Arab educational setting is unclear due to a lack of empirical studies regarding ICT use in learning. Quite clearly, the research body of the Arab world is still lacking sufficient research examining ICT practices within the educational context, specifically studies examining ICT and foreign or second language learning.

In fact, it has been asserted that conducting empirical research on the effectiveness, implementation, and integration of ICT in classroom teaching is important for enhancing learning $[16,22]$. Available research has explored teachers' perceptions and attitudes regarding ICT in a classroom teaching. However, far too little attention has been paid to the use of ICT from the Arab EFL (English as a foreign language) learners' perspective [23]. The latter is vital given the cultural framework in which interaction between students' perspectives and pedagogical practices has been minimal [23]. This study focuses on the complex interplay of number variables to explain Smartphone use among EFL Saudi university level students. These variables comprise students' attitudes, perceived ease of use, perceived usefulness, and vocabulary learning via Smartphones.
1.1. ICT and Language Teaching. In recent years, English language teaching (ELT) has undergone significant changes. For example, technology has contributed to the pedagogical shift from a teacher-centred approach to a learner-centred approach $[24,25]$. As well as the success of technology in education which has proven to be effective, some e-advances such as MALL have emerged. ELT has been affected by the latter due to rapid growth of technology inside and outside ELT classrooms. This development has attracted the attention of researchers to investigate its effect on language learning $[26,27]$. Recent attention has also been paid to the use of ICT in ELT in some of the third world countries [28]. At the microlevel, far too little focus has been paid to foreign or second language learning using technology such as Smartphones outside classroom setting. Smartphones, when effectively used, increase learning space. That is, the interaction between EFL learners and technology such as Smartphones may allow actual behaviour development which is in our case is learning vocabularies through Smartphones [29]. Another factor that may affect this interaction is the students' attitude that may affect learners' choices of interaction. Negative attitudes towards Smartphone utilisation in learning may result in neglecting this type of learning [30]. The literature credits technology with a part to play in constructing an alternative way that may allow a greater uptake of language skills to develop learners' language proficiency regardless of time and geographical distances [31, 32]. The students' foreign or second language proficiency is a major concern to educational bodies in Arab context and thus, the contribution of technology to develop language skills is becoming a pervasive resource for students if this technology is regarded as an effective alternative learning source [30]. The attempts to develop foreign or second language proficiency in Arab region, specifically the context of the current study, are a growing area for research investigations and this is discussed under methodology section that deals with educational initiatives to overcome the deficiency of language proficiency.

\section{Digital Devices in Vocabulary Acquisition}

The arrival of digital devices in the field of vocabulary learning brings questions to the educational researchers whether this type of learning is effective or not. To begin with, learning vocabulary is pivotal and essential to improve academic performance and language acquisition [33-35]. In this scope, McCarthy [33] explained that vocabularies are a cornerstone to expressing oneself meaningfully and communicating effectively. In addition, the growing infiltration of modern technology has influenced education of all levels. Today's theme of EFL/ESL classrooms is the interaction with technological products during learning processes. This contemporary advancements are seen in the use of Smartphones as a major communication medium, such as iPhone [36]. They are used for significant number of tasks in individuals learning process, such as studying a foreign or a second language $[36,37]$. With the use of Smartphones, learners of ESL/EFL tend to employ them for translating into their target language [38]. Moreover, one of the remarkable features that 
Smartphones have is the dictionary. Many students depend on this device to decipher the English language [38]. Related discussion on MALL shows that prior research could be categorized in two areas: developing mobile access learning materials (content-based) and out-of-class mobile learning materials (design-oriented) [39, 40].

The use of dictionaries is important for vocabulary acquisition [41]. For example, Knight [42] found that dictionaries develop students' vocabulary as well as comprehension. Cobb [43] asserts that learners should use dictionaries in lexical strategies, such as deducing word meanings from context and disregarding words. In a recent study, Stockwell [44] indicated a significant aspect of MALL in vocabulary learning. Each learner who participated in the study was linked to an intelligent tutor system via a mobile or desktop computer in order to take part in vocabulary activities. The system then generated a learner's profile that reports his/her most difficult areas in vocabulary learning. Moreover, in favour of using other devices, the use of mobile phones in language learning setting has been investigated in a Japanese context in which the results revealed that $99 \%$ respondents sent and received emails via mobile phones in their English language education setting [37]. More recently, Huang et al. [1] developed ubiquitous English vocabulary learning system to examine students' responses to such learning experience. The results of their study revealed that students' perspectives were positively and significantly influenced by the materials and the system characteristics. Surprisingly, despite the increasing number of studies related to ICT acceptance, little research has been conducted in the context of using Smartphones for foreign language vocabulary learning, specifically in an Arab context [45]. However, this research is targeted at investigating the field of Smartphone use in learning vocabulary. Furthermore, this research aims to provide knowledge of mobile-aided learning, specifically in the Arab region.

\section{Theoretical Framework and Hypotheses}

The technology acceptance model (TAM) has been employed to measure, predict, and explain individuals' behaviour in respect to their acceptance or rejection upon introducing new technology [46]. TAM postulates that the perceived usefulness and ease of use have an effect on users' attitude toward utilising technologies in contexts like education. It has been argued that this decision is affected by other factors such as attitude that contribute to rejecting or accepting technology in the learning process [47]. The current study employed TAM to measure, predict, and explain students' acceptance of Smartphones in vocabulary learning. TAM is considered a successful model in studying learners' behaviour regarding technology use in educational settings and Elearning [46]. The current study is particularly designed to investigate the factors that affect students' vocabulary development (VOC) through using Smartphones. Therefore, the above hypotheses were formulated to lead the current investigation. Figure 1 shows the current research model which originates from TAM. The current model consists of five hypotheses as described as follows.

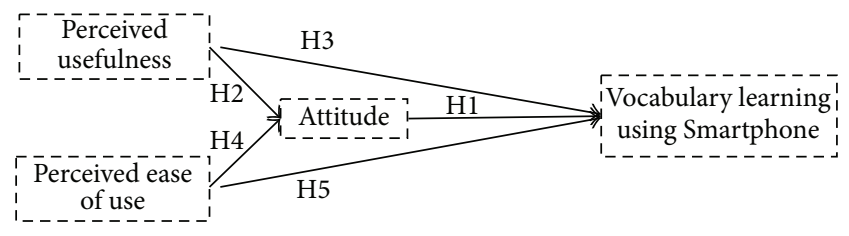

Figure 1: Research model.

3.1. Attitude. Although the attitude (ATT) factor has been widely investigated [10,48,49], the field of using Smartphones in learning is still in its infancy [1]. Venkatesh and Brown [50] defined attitude as an individual's favourable/unfavourable appraisal of the performance in question. Research field revealed that attitude has changed the actual use levels of specific technological applications or virtual learning systems [51]. With reference to the important role played by attitude in learning, we developed the following hypothesis.

$\mathrm{H1}$ : attitude is positively related to vocabulary development.

3.2. Perceived Usefulness. Previous studies have defined perceived usefulness (PU) as "the degree of which a person believes that using a particular system would enhance his or her job performance" [46]. Moreover, Davis et al. [47] found that perceived usefulness factor has a major effect on attitude. Research on students' perceptions of technology adaptation in learning has shown that technology potentials have determined their decisions regarding engagement in or use technology in learning $[52,53]$. Thus, the current research concluded that perceived usefulness is positively related to attitude and vocabulary development. The following hypotheses were formulated.

$\mathrm{H} 2$ : perceived usefulness is positively related to attitude.

H3: perceived usefulness is positively related to vocabulary development.

3.3. Perceived Ease of Use and Vocabulary Development. Davis [46] defined perceived ease of use (PEOU) as "the degree to which a person believes that using a particular system will be free of effort." Shih [49] found that perceived ease of use and perceived usefulness positively affect attitude factors. Remarkable research findings showed that students enjoyed the course website and found it easy to use which eventually affected their actual use of the site during the course [54]. The following two hypotheses were framed to examine the relationship between perceived ease of use and the two variables of attitude and vocabulary development.

H4: perceived ease of use is positively related to attitude.

H5: perceived ease of use is positively related to vocabulary development. 


\section{Methodology}

This research is quantitative in nature utilizing the SmartPLS software package [55] to analyse the data obtained from the study's sample. This method was implemented due to its representation of deductive approach that values the relationship between theory and research in which the emphasis is placed on testing theories implementation and specific hypotheses [56]. Moreover, a significant step in this examination process is to collect numerical data [57]. Because research on using Mobile phones (i.e., Smartphones) is few and far between in the Arab context, and thus collecting numerical data facilities, at present, is an essential understanding of using Mobile phones in learning within Arab context [58]. Our future expectations are around the significance of this research to other researchers in Arab context to further examine this field by building on the present study. The population of current research is English language learners in a preparatory year programme. This study was conducted in one of the major universities in Saudi Arabia. A total of 273 participants agreed to take part in the study. Those students were from the same cultural background. Those students are also a homogenous cluster and several exogenous factors can be simply controlled when using them as a sample. All collocated data were randomly selected from the students in order to meet the requirement of random selection of structural modeling. Table 1 in study's results section shows the students demographic profile.

4.1. The Context of the Study. The preparatory year programme (PYP) is designed for EFL students who lack proficiency in the English language in a university level. This programme comprises two semesters of four daily contact hours to help Saudi tertiary level students achieve better proficiency in English language. Students who successfully pass the PYP are eligible to commence their studies the following year. It is important to indicate that learners of English language in Saudi Arabia are found to have poor performance in the English language [59]. Therefore, several efforts have been made to successfully and effectively raise the students' proficiency level. For example, integrating ICT in classroom teaching and establishing a platform for online communication between students and teachers (known as jusur or "bridging"), which, however, are not applicable to all schools, colleges, and universities across the Kingdom of Saudi Arabia. However, a recent report by the United Nations Conference on Trade and Development (UNCTAD) [60] shows that Saudi Arabia has the largest number of mobile phone users worldwide. The report indicates that the Kingdom of Saudi Arabia has achieved 180 phones for everyone hundred residents, suggesting that Saudi Arabia holds world record in mobile ownershipper-capita.

4.2. Measurement. This section offers a description of the survey employed in this study. The variables' scales of attitude, perceived usefulness, and perceived ease of use were adapted from Davis [46] and comprises 3 items, 5 items, and 3 items, respectively. Moreover, vocabulary development measurement items were adapted from Chen et al. [61]. Vocabulary
TABLE 1: Respondents' profile.

\begin{tabular}{lcc}
\hline Variable & $N$ & Percentage \\
\hline Gender & 61 & \\
Male & 212 & $22.3 \%$ \\
$\quad$ Female & & $77.7 \%$ \\
Time spent on Smartphone use & 48 & \\
3-5 hours & 60 & $17.6 \%$ \\
6-8 hours & 165 & $22.0 \%$ \\
More than 9 hours & & $60.4 \%$ \\
\hline
\end{tabular}

development measurement items were deliberately chosen because they fit the aim of the current study. First, all items underwent a concise review by four experts in English language: one English language native speaker and three native speakers of Arabic. This concise review was done to ensure that all items in the questionnaire address the use of Smartphones for vocabulary development. In reviewing the statements obtained, items were modified to fit the study context (e.g., I use the dictionary to look for unfamiliar words using my Smartphone). Second, the present study followed a forward-back translation method to achieve the final Arabic version [62]. Third, the same experts reviewed the Arabic version to ensure its clarity and accuracy in addressing the vocabulary development using Smartphone by the Saudi students. In result, five items were finally agreed on. Moreover, a pilot study with 30 students was conducted to examine the validity and reliability of the study's implementation and to give preliminary results of data analysis. The feedback from the pilot study was used to improve the implementation of the measurement tool for clarity and completeness. The final version used a 5-point Likert scale, with 1 being "strongly agree" and 5 being "strongly disagree." The questionnaire was administered to English language learners.

4.3. Partial Least Squares (PLS). The research data were analysed using a popular structural equation modeling (SEM) approach, partial least squares. PLS was utilized due to nonexistence of assumptions concerning sample data distribution [63] and with a small sample size, PLS works well [64]. Therefore, the results obtained from PLS analysis are related to the investigation of the measurement model (see Figure 3). Therefore, the current model is examined on the basis of convergent and discriminant validity, construct reliability, and individual item loadings [65]. Subsequently, the structural model is assessed in order to deduce observations regarding causal relationships and their significance level [65].

\section{Results}

The demographic characteristics of the 273 respondents are summarized in Table 1 . The results indicated that $77 \%$ of the respondents are females. Moreover, the results showed that over $60.4 \%$ percent of the respondents spend more than 9 hours a day in using their Smartphones. The relevant assumption of this finding is that students have used their Smartphones for a number of daily activities (e.g., social interaction, 


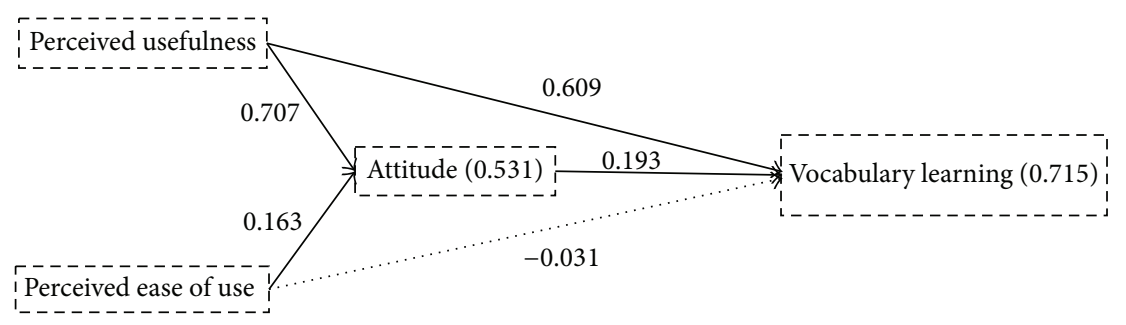

FIGURE 2: PLS results (brackets $=R^{2}$ for endogenous variables).

TABLE 2: Item loadings.

\begin{tabular}{lccccccc}
\hline \multicolumn{2}{c}{ Perceived usefulness } & \multicolumn{2}{c}{ Perceived ease of use } & \multicolumn{2}{c}{ Attitude } & \multicolumn{2}{c}{ Vocabulary learning } \\
Item & Value & Item & Value & Item & Value & Item & Value \\
\hline PU1 & 0.731 & PEOU1 & 0.846 & ATT1 & 0.887 & VOC1 & 0.820 \\
PU2 & 0.756 & PEOU2 & 0.867 & ATT2 & 0.815 & VOC2 & 0.803 \\
PU3 & 0.838 & PEOU3 & 0.897 & ATT3 & 0.662 & VOC3 & 0.777 \\
PU4 & 0.863 & & & & & VOC4 & 0.818 \\
PU5 & 0.789 & & & & & VOC5 & 0.749 \\
\hline
\end{tabular}

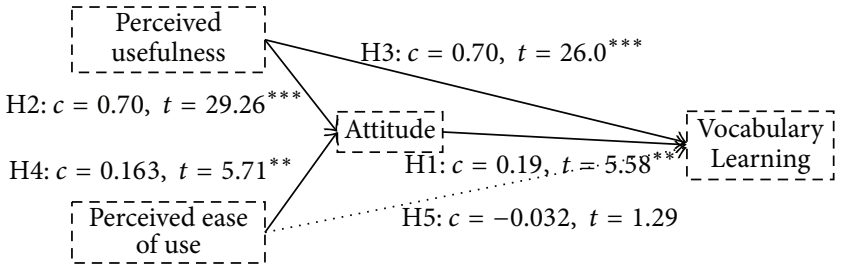

Figure 3: PLS Path Model. Note: $c=$ coefficient, $t=t$-value.

learning, and reading about topics under interest). It seems that Smartphones is reckoned to be pushing the access to individuals' interest anytime, anywhere. Thus, teachers may benefit students learning process through directing them to spend more time learning or working on activities that include Smartphones use. For example, teachers may ask their students to respond to questions, tasks, or activities on a blog.

In the current work, it can be noticed that the number of female student partisans outweighed the number of male student participants for some reasons. First, female students were more responsive to research participation than males. Second, in Arab countries female students have shown great interest to study a foreign language using technology, and they hold beliefs that mastering a foreign language may help in securing future career. In addition, all student participants were instructed to respond to their use of Smartphones in vocabulary learning survey, mostly females, and only those who agreed to this instruction were selected.

Table 2 reveals individual item loadings, the values should exceed 0.7, as recommended by Chin [66]. As shown in Table 2, all items exceeded 0.7. Exception was noted in ATT3 item which, however, produced acceptable value (i.e., greater than 0.5) as recommended by Chin [66].

The current research analysis techniques employed Cronbach's alpha and composite reliability to assess construct reliability, with considerable emphasis on composite reliability as proposed by Roldán and Leal [65]. Nunnally recommended that a value of 0.7 should be used as a threshold [67]. Table 3 reveals the results of all constructs satisfactory values for composite reliability. Moreover, all constructs exceeded the threshold of Cronbach's alpha value of 0.7 as recommended by Nunnally [67]. Continuously, Table 3 shows convergent validity results of average variance extracted (AVE) of all constructs under the study. Fornell and Larcker proposed that AVE value should be greater than 0.5 in which, however, all constructs exceeded the proposed threshold [68].

Discriminant validity was established on Fornell and Larcker "criterion" where the root of the average variance extracted should be higher than its correlation with other constructs [68]. Table 4 shows the results of discriminant validity in which the results of constructs produced good results.

5.1. Research Structural Model. The structural model used in the study has been assessed using bootstrapping technique with 500 resamples [66]. $t$-values were examined on a two-tail test with significance levels of $P<0.05$ : $t$-value $>1.972\left({ }^{*}\right)$, $P<0.01: t$-value $>2.601\left(^{* *}\right)$, and $P<0.001: t$-value $>3.340$ $\left({ }^{* * *}\right)$. Figure 2 reveals the outcomes of direct and indirect effects. Table 5 indicates more details of the significant and insignificant (dot arrow) paths of the proposed model. The results obtained confirmed the majority of the hypotheses, at various significance levels (see Table 5). The variance explained $\left(R^{2}\right)$ is shown in Figure 2, which according to Cohen [69] values of $>0.02$ has a weak effect, $>0.15$ has a moderate effect, and $>0.35$ has a strong effect. It should be noted that each path symbolizes each hypothesis. The $R^{2}$ of each of the endogenous variables was as follows: attitude: 0.531 and vocabulary development: 0.715 . Figure 2 reveals the most important direct effect of perceived usefulness on vocabulary development $0.609^{* * *}(\mathrm{H} 3)$ and attitude direct effect on vocabulary development $0.193^{* * *}$ (H1). The exogenous variables successfully explained $71.5 \%$ of the variance of vocabulary development. Moreover, the direct effect of 
TABLE 3: Results of the measurement model.

\begin{tabular}{lccc}
\hline Construct & Cronbach's alpha $(\alpha)$ & Composite reliability & Average variance extracted \\
\hline Attitude & 0.702 & 0.834 & 0.63 \\
Perceived ease of use & 0.847 & 0.903 & 0.758 \\
Perceived usefulness & 0.857 & 0.896 & 0.635 \\
Vocabulary learning & 0.853 & 0.895 & 0.630 \\
\hline
\end{tabular}

TABLE 4: Discriminant validity of the measurement model.

\begin{tabular}{lcccc}
\hline Construct & Attitude & Perceived ease of use & Perceived usefulness & Vocabulary learning \\
\hline Attitude & $(0.79)$ & & & \\
Perceived ease of use & 0.1798 & $(0.87)$ & $(0.80)$ \\
Perceived usefulness & 0.5106 & 0.024 & 0.314 & $(0.79)$ \\
Vocabulary learning & 0.6043 & 0.0408 & \\
\hline
\end{tabular}

Note: figures in parentheses represent the squared root of the average variance extracted, while the others represent the correlations.

TABLE 5: Summary of hypotheses testing.

\begin{tabular}{lcccc}
\hline Path & Coefficient & $t$-value & Significance & Remark \\
\hline ATT $\rightarrow$ VOC & 0.1925 & 5.5887 & $P<0.01^{* *}$ & Supported \\
PEOU $\rightarrow$ ATT & 0.1629 & 5.7119 & $P<0.01^{* *}$ & Supported \\
PEOU $\rightarrow$ VOC & -0.0328 & 1.2931 & $P>0.05$ & Not supported \\
PU $\rightarrow$ ATT & 0.7072 & 29.2675 & $P<0.001^{* * *}$ & Supported \\
PU $\rightarrow$ VOC & 0.7012 & 26.0044 & $P<0.001^{* * *}$ & Supported \\
\hline$* *$ P
\end{tabular}

${ }^{* *} P<0.01,{ }^{* * *} P<0.001$.

PU on ATT has accounted for $0.707^{* * *}(\mathrm{H} 2)$, which also shows us that the PU is a very successful predictor of learner's utilization of Smartphones in vocabulary learning. In addition, the direct effect of PEOU has accounted for $0.163^{* * *}$ (H4). Together, the exogenous variables have explained 53\% of the variance of attitude. Finally, PEOU does not have a direct significant effect on vocabulary development. H5 must, therefore, be rejected.

Particularly, PU is associated with a very strong significant relationship with ATT using Smartphones and VOC (H2: $P<0.001$ and H3: $P<0.001$, resp.). Additionally, the relationship (H4) between PEOU and ATT using Smartphones was confirmed with a significance level as well (H4: $P<0.00)$. However, the relationship between PEOU and VOC did not prove to be significant (H5: $P>0.05)$. Finally, ATT using Smartphones affects positively VOC (H1: $P<$ $0.01)$.

Moreover, Table 5 provides summary of the proposed model and hypotheses testing. In summation, the path coefficient between ATT and VOC was $0.19, P<0.01$, which indicates that ATT had a positive and significant impact on VOC. Second, the path coefficient between PEOU and ATT was $0.16, P<0.01$, which indicates that PEOU had a positive and significant impact on ATT. Third, the path coefficient between PEOU and VOC was $-0.03, P>0.05$ which indicates that PEOU did not have an impact on VOC. Fourth, the path coefficient between PU and ATT was 0.70, $P<0.001$, which indicates that PU had a positive and significant impact on ATT. Fifth, the path coefficient between
PU and VOC was $0.70, P<0.001$, which indicates that PU had a positive and significant impact on VOC.

\section{Discussion}

Notably, real concerns about the use of mobile phones in education accompany the recognition of the acceptance of such learning path in foreign or second language education. In this research, an attempt to approach the topic of students' acceptance of using Smartphones in vocabulary learning was carried out. Thus, by leveraging the use of Smartphones in education field, specifically learning second or foreign language, students learning process could be expanded and developed. The results of this study demonstrate similarities among results of a variety of research investigations $[1,70,71]$. This study was conducted among PYP students in Saudi Arabia. Results of the demographic variables showed that $60.4 \%$ of sample spends over nine hours a day using their Smartphones. Those students devoted some of Smartphone use time to learn and develop their English language vocabularies. This has confirmed that technology has changed PYP students daily lives activities including learning. Interestingly, a majority of factors have been confirmed to have a significant direct effect on vocabulary learning via Smartphones. The proposed model examined factors that contribute to the use of Smartphones in learning English language vocabulary. In particular, usefulness and ease of use were proved to be significant determiners of students' attitude toward using 
Smartphones in learning vocabulary. In contrary, ease of use did not prove to be a significant determiner of vocabulary learning factor. However, attitude was found to be related significantly to vocabulary learning factor. The research model indicated a relationship between ease of use and vocabulary learning, which proved to be a nonsignificant relationship, existing between both factors.

Of importance, attitude factor was found to have significant impact on vocabulary learning using Smartphone (H1). This result seems to indicate that preparatory year students hold positive attitude towards learning English vocabulary because they are in need for developing adequate level of English language proficiency, which will benefit their studies. This need has been the driving force of learning using Smartphone.

The results show a greater impact of PU $(\mathrm{H} 2)$ than PEOU (H4) on the attitude factor and suggest that students' attitude towards information and explanations of vocabulary pivots on greater intention on making vocabulary explanations easier to understand through interesting methods such as pictures or games specifically for EFL learners [72]. The examined relationships between PU, PEOU, and ATT suggest that PU, PEOU of Smartphones, and students' attitudes are imperative in predicting students' interest in using Smartphones for learning, in particular for vocabulary development. Above all, the current research further contends that students will use Smartphones for vocabulary learning if they find this usage to be enjoyable, interesting, beneficial to their learning process, and easy to use in its own right, directed particularly by Smartphones' ease of use.

Furthermore, the result of path analysis between PU and vocabulary learning (H3) suggests that students regarded vocabulary learning through Smartphones as useful to their learning process. Preparatory year students are seeking sources of beneficial learning to achieve adequate level of English language proficiency and this motive has clearly affected their technological interest during their learning process. This motive is also surrounded by other factors such as the need to knowledge acquisition, social interaction, and studying in English speaking countries in which these factors happen to need adequate level of English language proficiency.

However, the result of PEOU and VOC (H5) suggests that students might have problems with interface design, such as forcing them to login in order to use or purchase the product, which requires effort in which the users think this effort should be used to other tasks. Thus, students feel that they have no control over their learning. The ease of use of applications, such as dictionaries span, should be taken into account. To support students' ease of use, various forms of applications' interfaces should be tested and evaluated by their respective users. This may help in ease of use domain that intends to support effective learning. Designers and products developers, therefore, should pay careful attention to vocabulary learning products [73].

More importantly, the result of the relationship between attitude and vocabulary learning is attributed in the sense that educational institutions in most Arab countries such as Jordan and the Kingdom of Saudi Arabia (KSA) have set new educational polices regarding pursing higher education degrees where English language has become the medium of instruction for most of its programmes. Therefore, students are in a position in which they must learn academic English. One good example of these polices is implemented KSA, where all students enrolled at the tertiary level must pass the foundation year program. They must attend a weekly 20 -contact hour class in the English language. Additionally, these results are also supported by the demographic results of the students where 165 students spent over 9 hours daily using their Smartphones in different daily life activities including learning. This result suggests that teachers of the English language should pay careful attention to employing creative activities and games that help students in learning through the use of Smartphones. Above that, the result of time spent on Smartphone usage suggests that a wider space of interaction between students and teachers in a learning situation out- and inside classrooms can be approached.

\section{Conclusions}

This research aimed at examining Saudi students' behavioural factors that affect employing Smartphones in vocabulary learning. To explore these factors, the technology acceptance model was employed to create the study model and partial least squares were utilized to evaluate the study's model. The study reveals that most of the factors under the investigation were found to be significant determiners of vocabulary learning via Smartphones. In specific, usefulness and ease of use proved to be significant predictors of students' attitude to use Smartphone for vocabulary learning. In contrary, ease of use did not significantly relate to vocabulary learning factor. Attitude and usefulness factors significantly affect vocabulary-learning factor.

In specific, and considering the difference in the percentages of females (78\%) and males (22\%), the results of current work may have been affected by the gender of the sample analysed. We should be warned that if the proportion was different, and addressing the context of the study examined, it could strengthen the relationship between PEOU and ATT, for example. Further, it seems, in the light of current percentage of female participation, that the relevance of working with smart technology is a prerequisite for optimal foreign language learning which is specifically important for women in Arabia. This scenario may explain why girls perform better in language learning in Arabia as well as willingness to respond to research involved in this area.

The research practical implications point out first to teachers of English language in a tertiary setting and specifically to male teachers since education in Arabia is segregated based on gender. The number of hours spent on using Smartphones by students can be seen as promising factor in students learning and, therefore, teachers are encouraged to apply creative exercises that invest students' time outside the classroom setting. Knowledge of time devoted by students in using Smartphones, specifically by females, may secure a better preparation for language learning activities by teachers that cater the variation between genders. Second, in this 
research, student's attitude was positively held in vocabulary learning using Smartphone. This implies that using Smartphones may motivate students to maximize their vocabulary learning and, accordingly, teachers may benefit their students learning process through creating creative activities that address language learning skills. Having a low response rate from male students can be seen as a useful indicator for male teachers of their students' attitude towards using technology in learning. This may help male teachers in designing a systematic plan for motivating male students to employ technology in learning. The third implication is drawn from the students' perceived usefulness of employing Smartphone in vocabulary learning, which is seen as an alternative tool of learning to them. This tool should capture the interest of software designers' attention in order to design more easy to use applications' interfaces that improve students learning effectively and efficiently.

The future of using Smartphones in learning is promising; students in high-income countries will have the chance to explore a new way of learning. Therefore, we suggest that future work should be directed towards understanding students' attitudes in employing this technology in mediumand low-income countries in order to understand how their counterparts in these countries view foreign language vocabulary learning via Smartphone. Other cultural contexts would be of an interest to researchers in the Arab world as well. Age and gender of learners may extend the proposed framework to understand how males, females, young, and adults use Smartphones in foreign language vocabulary learning. Moreover, cultural background and family income are considerable factors that need to be further investigated concerning their effect on students' perceptions regarding vocabulary learning via Smartphones.

However, it is important to note that the current research's limitations originate from the sample of the study; that is, our sample was from the first year undergraduates' students in PYP. Therefore, our results correspond to those students and it might have been different if this research was conducted in another context containing different variables, such as second, third, or fourth year students, and correlated to the number of years the students have had a Smartphone.

\section{Conflict of Interests}

The authors declare that there is no conflict of interests regarding the publication of this paper.

\section{References}

[1] Y.-M. Huang, S.-H. Huang, and Y.-T. Lin, "A ubiquitous English vocabulary learning system: evidence of active/passive attitudes vs. usefulness/ease-of-use," Computers and Education, vol. 58, no. 1, pp. 273-282, 2012.

[2] Y. Sun and Q. Dong, "An experiment on supporting children's English vocabulary learning in multimedia context," Computer Assisted Language Learning, vol. 17, no. 2, pp. 131-147, 2004.

[3] Y.-M. Huang, Y.-T. Lin, and S.-C. Cheng, "Effectiveness of a mobile plant learning system in a science curriculum in
Taiwanese elementary education," Computers \& Education, vol. 54, no. 1, pp. 47-58, 2010.

[4] L.-H. Wong and C.-K. Looi, "Mobile-assisted vocabulary learning in real-life setting for primary school students: Two case studies," in Proceedings of the 6th IEEE International Conference on Wireless, Mobile and Ubiquitous Technologies in Education (WMUTE '10), pp. 88-95, IEEE, April 2010.

[5] C. Kim, M. Mirusmonov, and I. Lee, "An empirical examination of factors influencing the intention to use mobile payment," Computers in Human Behavior, vol. 26, no. 3, pp. 310-322, 2010.

[6] J.-R. Chou and S.-W. Hsiao, "A usability study on humancomputer interface for middle-aged learners," Computers in Human Behavior, vol. 23, no. 4, pp. 2040-2063, 2007.

[7] H. H. Chang and I. C. Wang, "An investigation of user communication behavior in computer mediated environments," Computers in Human Behavior, vol. 24, no. 5, pp. 2336-2356, 2008.

[8] P. S. Klein, O. Nir-Gal, and E. Darom, "Use of computers in kindergarten, with or without adult mediation; effects on children's cognitive performance and behavior," Computers in $\mathrm{Hu}$ man Behavior, vol. 16, no. 6, pp. 591-608, 2000.

[9] L. Zhou, J. K. Burgoon, D. Zhang, and J. F. Nunamaker, "Language dominance in interpersonal deception in computermediated communication," Computers in Human Behavior, vol. 20, no. 3, pp. 381-402, 2004.

[10] S.-S. Liaw, H.-M. Huang, and G.-D. Chen, "Surveying instructor and learner attitudes toward e-learning," Computers and Education, vol. 49, no. 4, pp. 1066-1080, 2007.

[11] J. Rubagiza, E. Were, and R. Sutherland, "Introducing ICT into schools in Rwanda: educational challenges and opportunities," International Journal of Educational Development, vol. 31, no. 1, pp. 37-43, 2011.

[12] G. Shaw and N. Marlow, "The role of student learning styles, gender, attitudes and perceptions on information and communication technology assisted learning," Computers \& Education, vol. 33, no. 4, pp. 223-234, 1999.

[13] R. Sutherland, V. Armstrong, S. Barnes et al., "Transforming teaching and learning: embedding ICT into everyday classroom practices," Journal of Computer Assisted Learning, vol. 20, no. 6, pp. 413-425, 2004.

[14] C. S. Chai, T. Teo, and C. B. Lee, "Modelling the relationships among beliefs about learning, knowledge, and teaching of pre-service teachers in Singapore," Asia-Pacific Education Researcher, vol. 19, no. 1, pp. 25-42, 2010.

[15] J. Gil-Flores, J.-J. Torres-Gordillo, and V.-H. Perera-Rodríguez, "The role of online reader experience in explaining students' performance in digital reading," Computers and Education, vol. 59, no. 2, pp. 653-660, 2012.

[16] J. Enrique Hinostroza, C. Labbé, M. Brun, and C. Matamala, "Teaching and learning activities in Chilean classrooms: is ICT making a difference?" Computers and Education, vol. 57, no. 1, pp. 1358-1367, 2011.

[17] M. Fishbein and I. Ajzen, Predicting and Changing Behavior, Taylor \& Francis, 2010.

[18] I. Ajzen, "Perceived behavioral control, self-efficacy, locus of control, and the theory of planned behavior," Journal of Applied Social Psychology, vol. 32, no. 4, pp. 665-683, 2002.

[19] S. H. Jin, "Visual design guidelines for improving learning from dynamic and interactive digital text," Computers and Education, vol. 63, pp. 248-258, 2013. 
[20] Y. Al-Saggaf, "The online public sphere in the arab world: the war in Iraq on the Al Arabiya website," Journal of ComputerMediated Communication, vol. 12, no. 1, pp. 311-334, 2006.

[21] A. Albirini, "Teachers'attitudes toward information and communication technologies: the case of Syrian EFL teachers," Computers and Education, vol. 47, no. 4, pp. 373-398, 2006.

[22] J. Tondeur, H. van Keer, J. van Braak, and M. Valcke, "ICT integration in the classroom: challenging the potential of a school policy," Computers and Education, vol. 51, no. 1, pp. 212-223, 2008.

[23] R. Bataineh and A. Baniabdelrahman, "Jordanian EFL students' perceptions of their computer literacy," International Journal of Education and Development Using ICT, vol. 2, no. 2, pp. 35-50, 2006.

[24] J. C. Richards, The Context of Language Teaching, Cambridge University Press, Cambridge, UK, 1985.

[25] K. Facer, R. Joiner, D. Stanton, J. Reid, R. Hull, and D. Kirk, "Savannah: mobile gaming and learning?" Journal of Computer Assisted Learning, vol. 20, no. 6, pp. 399-409, 2004.

[26] M. M. Yunus, M. A. Lubis, and C. P. Lin, "Language learning via ICT: uses, challenges and issues," WSEAS Transactions on Information Science and Applications, vol. 6, no. 9, pp. 1453-1467, 2009.

[27] S. S.-C. Young, "Integrating ICT into second language education in a vocational high school," Journal of Computer Assisted Learning, vol. 19, no. 4, pp. 447-461, 2003.

[28] H. Salehi and Z. Salehi, "Integration of ICT in language teaching: challenges and barriers," in Proceedings of the 3rd International Conference on e-Education, e-Business, e-Management and e-Learning, IACSIT Press, Singapore, 2012.

[29] I. Ajzen, "Nature and operation of attitudes," Annual Review of Psychology, vol. 52, no. 1, pp. 27-58, 2001.

[30] J. A. Kalmbach, "Just in time for the 21st century," TechTrends, vol. 39, no. 6, pp. 29-32, 1994.

[31] M. Celce-Murcia, "Rethinking the role of communicative competence in language teaching," in Intercultural Language Use and Language Learning, E. A. Soler and M. P. S. Jordà, Eds., pp. 41-57, Springer, Berlin, Germany, 2007.

[32] L. R. Naigles and L. Mayeux, "Television as incidental language teacher," in Handbook of Children and the Media, D. Singer and J. Singer, Eds., pp. 135-152, Sage, London, UK, 2001.

[33] M. McCarthy, Vocabulary, Oxford University Press, 1990.

[34] S. Rott, "The effect of exposure frequency on intermediate language learners' incidental vocabulary acquisition and retention through reading," Studies in Second Language Acquisition, vol. 21, no. 4, pp. 589-619, 1999.

[35] P. Thornton and C. Houser, "Using mobile phones in education," in Proceedings of the 2nd IEEE International Workshop on Wireless and Mobile Technologies in Education (WMTE '04), pp. 3-10, IEEE, JungLi, Taiwan, March 2004.

[36] R. N. Madeira, V. F. Pires, O. P. Dias, and J. F. Martins, "Development of a mobile learning framework for an analog electronics course," in Proceedings of the IEEE Education Engineering Conference (EDUCON '10), pp. 561-567, Madrid, Spain, April 2010.

[37] P. Thornton and C. Houser, "Using mobile phones in English education in Japan," Journal of Computer Assisted Learning, vol. 21, no. 3, pp. 217-228, 2005.

[38] M. Y. Fan, "Frequency of use, perceived usefulness, and actual usefulness of second language vocabulary strategies: a study of Hong Kong learners," The Modern Language Journal, vol. 87, no. 2, pp. 222-241, 2003.
[39] A. Kukulska-Hulme and L. Shield, "An overview of mobile assisted language learning: can mobile devices support collaborative practice in speaking and listening," EuroCALL, 15: p. 2008, 2007.

[40] L.-H. Wong and C.-K. Looi, "Vocabulary learning by mobileassisted authentic content creation and social meaning-making: two case studies," Journal of Computer Assisted Learning, vol. 26, no. 5, pp. 421-433, 2010.

[41] O. Mich, E. Pianta, and N. Mana, "Interactive stories and exercises with dynamic feedback for improving reading comprehension skills in deaf children," Computers \& Education, vol. 65, pp. 34-44, 2013.

[42] S. Knight, "Dictionary use while reading: the effects on comprehension and vocabulary acquisition for students of different verbal abilities," The Modern Language Journal, vol. 78, no. 3, pp. 285-299, 1994

[43] T. Cobb, The Comparison of Korean Students' Vocabulary Learning Strategies, McGill University, Montreal, Canada, 2004.

[44] G. Stockwell, "Vocabulary on the move: Investigating an intelligent mobile phone-based vocabulary tutor," Computer Assisted Language Learning, vol. 20, no. 4, pp. 365-383, 2007.

[45] D. Mcconatha, M. Praul, and M. J. Lynch, "Mobile learning in higher education: an empirical assessment of a new educational tool," Turkish Online Journal of Educational Technology, vol. 7, no. 3, pp. 1-8, 2008.

[46] F. D. Davis, "Perceived usefulness, perceived ease of use, and user acceptance of information technology," MIS Quarterly, vol. 13, no. 3, pp. 319-339, 1989.

[47] F. D. Davis, R. P. Bagozzi, and P. R. Warshaw, "User acceptance of computer technology: a comparison of two theoretical models," Management science, vol. 35, no. 8, pp. 982-1003, 1989.

[48] H. M. Selim, "Critical success factors for e-learning acceptance: confirmatory factor models," Computers \& Education, vol. 49, no. 2, pp. 396-413, 2007.

[49] H.-P. Shih, "Using a cognition-motivation-control view to assess the adoption intention for Web-based learning," Computers \& Education, vol. 50, no. 1, pp. 327-337, 2008.

[50] V. Venkatesh and S. A. Brown, "A longitudinal investigation of personal computers in homes: adoption determinants and emerging challenges," MIS Quarterly, vol. 25, no. 1, pp. 71-102, 2001.

[51] B. Sumak, G. Polancic, and M. Hericko, "An empirical study of virtual learning environment adoption using UTAUT," in Proceedings of the 2nd International Conference on Mobile, Hybrid, and On-Line Learning (ELML '10), pp. 17-22, February 2010.

[52] C. Lai, Q. Wang, and J. Lei, "What factors predict undergraduate students' use of technology for learning? A case from Hong Kong," Computers and Education, vol. 59, no. 2, pp. 569-579, 2012.

[53] W. Clark, K. Logan, R. Luckin, A. Mee, and M. Oliver, "Beyond web 2.0: mapping the technology landscapes of young learners," Journal of Computer Assisted Learning, vol. 25, no. 1, pp. 56-69, 2009.

[54] H. M. Selim, "An empirical investigation of student acceptance of course websites," Computers and Education, vol. 40, no. 4, pp. 343-360, 2003.

[55] C. M. Ringle, S. Wende, and A. Will, "SmartPLS 2.0 (M3) Beta," 2005, http://www.smartpls.de/.

[56] A. Bryman, Social Research Methods, Oxford University Press, 2012. 
[57] D. Muijs, Doing Quantitative Research in Education with SPSS, SAGE Publications Limited, New York, NY, USA, 2010.

[58] J. W. Creswell, Research Design: Qualitative, Quantitative, and Mixed Methods Approaches, Sage, Beverley Hills, Calif, USA, 2nd edition, 2003.

[59] M. G. McMullen, "Using language learning strategies to improve the writing skills of Saudi EFL students: will it really work?" System, vol. 37, no. 3, pp. 418-433, 2009.

[60] The United Nations Conference on Trade and Development (UNCTAD), 2011, http://unctad.org/en/Pages/Publications.aspx.

[61] M. H. Chen, P. J. Gualberto, and C. L. Tameta, "The development of metacognitive reading awareness inventory," TESOL Journal, vol. 1, pp. 43-57, 2009.

[62] B. V. Yamkovenko, E. Holton III, and R. A. Bates, "The Learning Transfer System Inventory (LTSI) in Ukraine: the cross-cultural validation of the instrument," Journal of European Industrial Training, vol. 31, no. 5, pp. 377-401, 2007.

[63] K. Joreskog and H. Wold, "The ML and PLS techniques for modeling with latent variables," in Systems Under Indirect Observation, K. Joreskog and H. Wold, Eds., pp. 263-270, North-Holland, New York, NY, USA, 1982.

[64] W. W. Chin, P. R. Newsted, and R. H. Hoyle, "Structural equation modeling analysis with small samples using partial least squares," in Statistical Strategies for Small Sample Research, R. H. Hoyle, Ed., Sage, Thousand Oaks, Calif, USA, 1999.

[65] J. L. Roldán and A. Leal, "A validation test of an adaptation of the DeLone and McLean's model in the Spanish EIS field," in Critical Reflections on Information Systems: A Systemic Approach, J. J. Cano, Ed., pp. 66-84, IGI Publishing, Hershey, Pa, USA, 2003.

[66] W. W. Chin, "The partial least squares approach for structural equation modeling," in Modern Methods for Business Research, G. A. Marcoulides, Ed., pp. 295-358, Lawrence Erlbaum, Mahwah, NJ, USA, 1998.

[67] J. Nunnally, Psychometric Methods, McGraw-Hill, New York, NY, USA, 1978.

[68] C. Fornell and D. F. Larcker, "Evaluating structural equation models with unobservable variables and measurement error," Journal of Marketing Research, vol. 18, no. 1, pp. 39-50, 1981.

[69] J. Cohen, Statistical Power Analysis for the Behavioral Sciences, Lawrence Erlbaum, Hillsdale, Mich, USA, 1988.

[70] R. G. Saadé, F. Nebebe, and W. Tan, "Viability of the "technology acceptance model" in multimedia learning environments: a comparative study," Interdisciplinary Journal of Knowledge and Learning Objects, vol. 3, no. 2, pp. 175-184, 2007.

[71] M. Masrom, "Technology acceptance model and E-learning," in Proceedings of the 12th International Conference on Education, Universiti Brunei Darussalam, Darussalam, Brunei, May 2007.

[72] A. Uberman, "The use of games for vocabulary presentation and revision,” English Teaching Forum, vol. 36, no. 1, pp. 20-27, 1998.

[73] J. Underwood, R. Luckin, and N. Winters, "Managing resource ecologies for mobile, personal and collaborative self-directed language learning," Procedia-Social and Behavioral Sciences, vol. 34, pp. 226-229, 2012. 

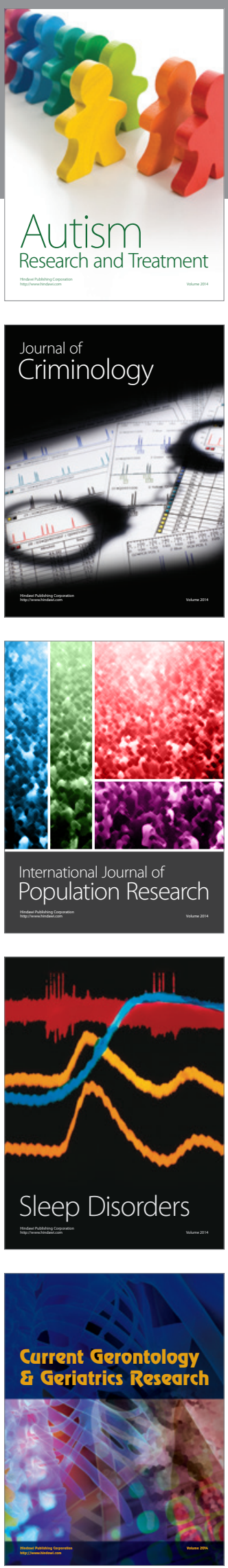
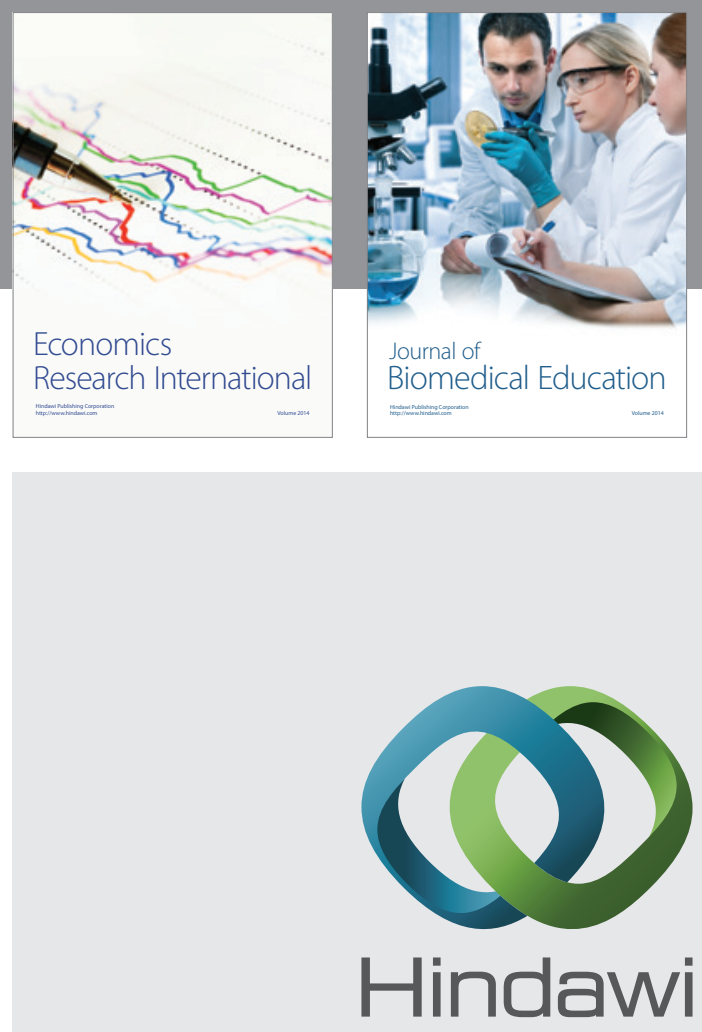

Submit your manuscripts at

http://www.hindawi.com
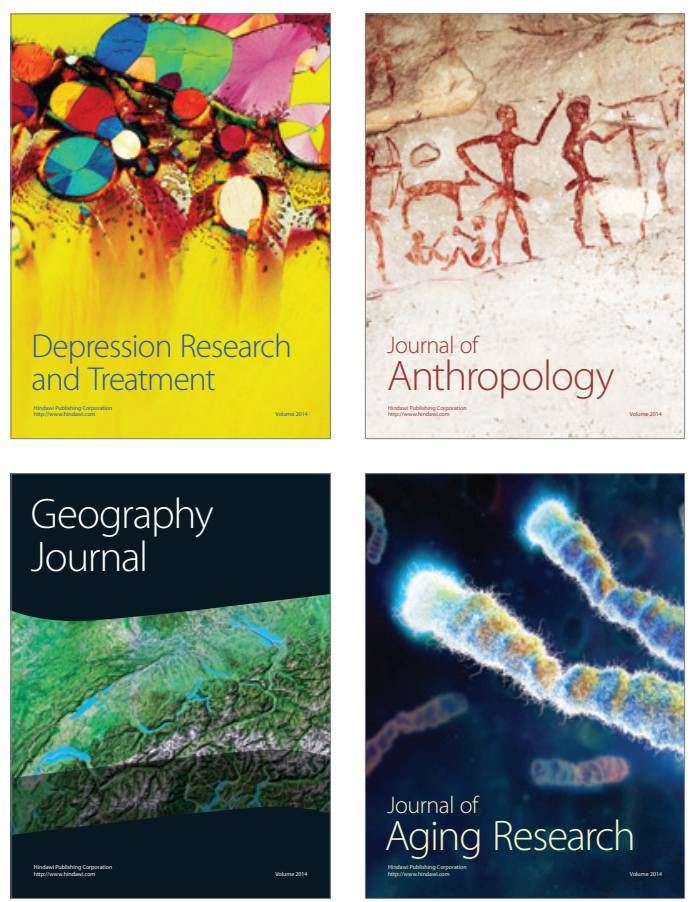
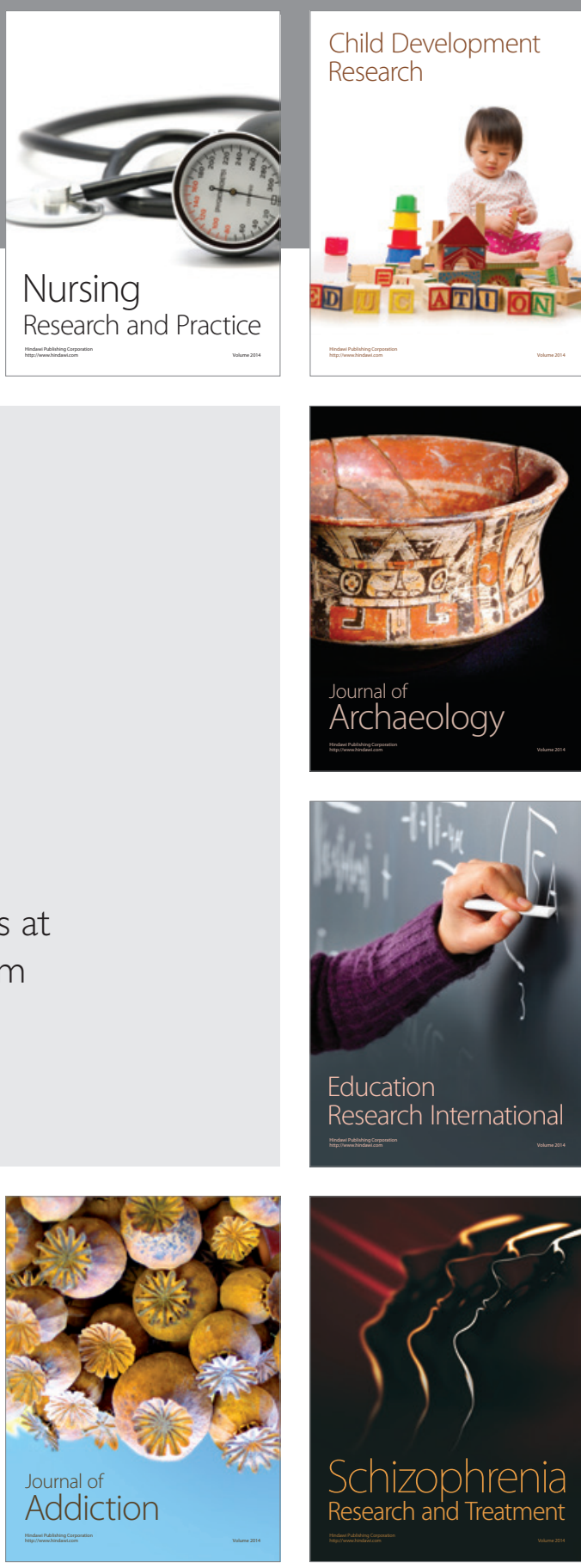

(D)
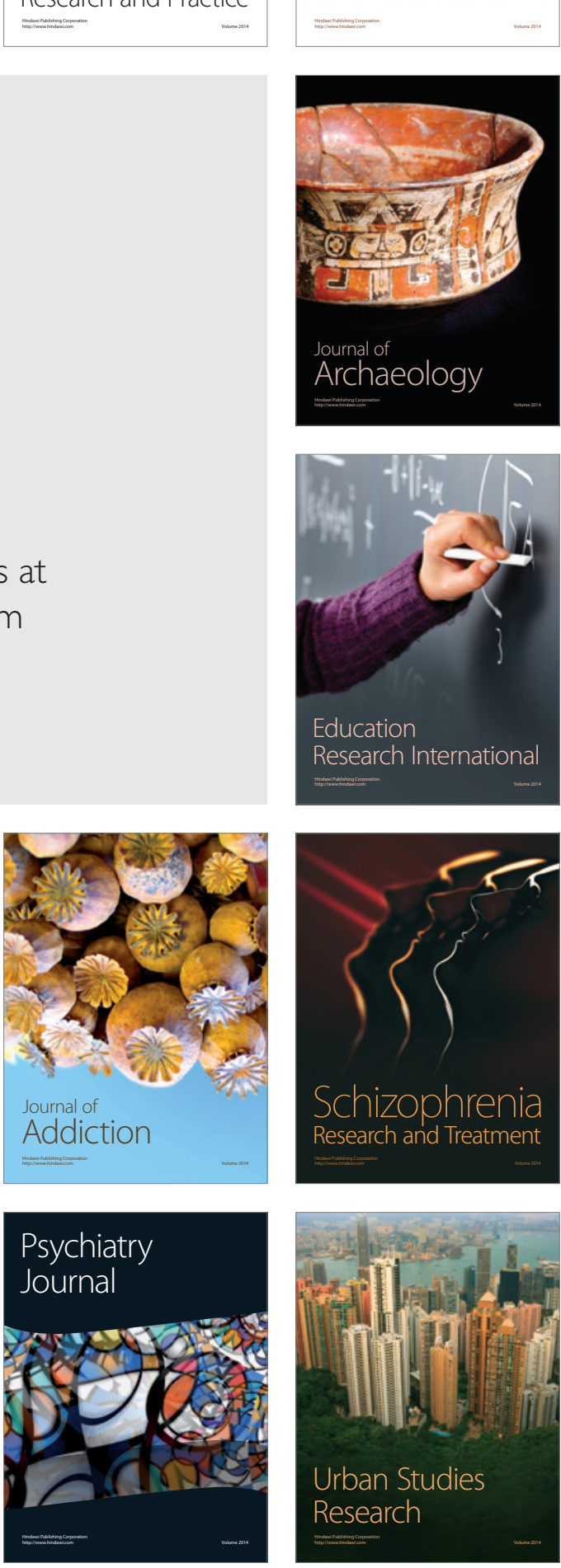